\begin{tabular}{|c|c|c|c|}
\hline & $\begin{array}{l}\text { Survived<12 months } \\
(n=30)\end{array}$ & $\begin{array}{l}\text { Survived>12 months } \\
(\mathrm{n}=43)\end{array}$ & $\begin{array}{l}\mathrm{P} \\
\text { Value }\end{array}$ \\
\hline Age (years) & $71.1(64.3-74.8)$ & $65.5(62.4-75.3)$ & $p=0.47$ \\
\hline Number (\%) Male & $10(33 \%)$ & $24(56 \%)$ & $\mathrm{p}=0.06$ \\
\hline BMI $\left(\mathrm{kg} / \mathrm{m}^{2}\right)$ & $21.3(17.2-25.3)$ & $26.1(210-30.8)$ & $\mathrm{p}=0.03$ \\
\hline $\begin{array}{l}\text { Number }(\%) \text { initiated after } \\
\text { acute admission }\end{array}$ & $24(80 \%)$ & $31(72 \%)$ & $p=0.44$ \\
\hline $\begin{array}{l}\text { Forced Expiratory Volume in } \\
1 \mathrm{~s}(\mathrm{~L})\end{array}$ & $0.65(0.44-0.85)$ & $0.82(0.52-0.95)$ & $\mathrm{p}=0.89$ \\
\hline Baseline pC02 (kPa) & $9.9(8.4-11.7)$ & $9.2(8.2-10.7)$ & $p=0.33$ \\
\hline $\begin{array}{l}\text { Inspiratory Positive Airway } \\
\text { Pressure }\left(\mathrm{cm} \mathrm{H}_{2} \mathrm{O}\right)\end{array}$ & $22(19-28)$ & $25(20-27)$ & $p=0.23$ \\
\hline $\begin{array}{l}\text { Expiratory Positive Airway } \\
\text { Pressure }\left(\mathrm{cm} \mathrm{H}_{2} \mathrm{O}\right)\end{array}$ & $5(5-6)$ & $5(4-5)$ & $p=0.02$ \\
\hline $\begin{array}{l}\text { Number (\%) using } \\
\text { NIV } \geq 4 \text { hours per night }\end{array}$ & $20(67 \%)$ & $39(90 \%)$ & $p=0.1$ \\
\hline
\end{tabular}

Data are presented as median (Interquartile Range)

Discussion 109 (73\%) patients with COPD and hypercapnic respiratory failure continued using NIV after set up. Our data demonstrates lower body mass index was significantly associated with surviving $<12$ months after starting NIV. Patients who survived more than 12 months showed a non-significant trend to be male, younger and use NIV for more than 4 hours each night at higher inspiratory pressures. An unexpected finding was that patients intolerant of NIV showed a trend to longer survival, compared to those who continued with NIV. This may be due to the small number of patients with full data, or that $50 \%$ of these patients had stable hypercapnic respiratory failure at NIV initiation, compared to $25 \%$ in the patients who used NIV.

Conclusions These observations highlight the need for careful patient selection when considering which patients with COPD may benefit from home NIV, an awareness of the different features that may contribute to survival, and subsequent attention to ventilator settings and compliance once the treatment has begun.

\section{P124 EARLY EXPERIENCE WITH 2-WAY REMOTE MONITORING FOR THE INITIATION OF VOLUME- ASSURED HOME NON-INVASIVE VENTILATION}

G McDowell, D MacFarlane, R Tourish, C Canavan, A Brown, H Ambler, C Carlin. Queen Elizabeth University Hospital, Glasgow, UK

\subsection{6/thoraxjnl-2017-210983.266}

Introduction The prevalence of conditions requiring nocturnal breathing support is increasing. 2-way remote monitoring via a cloud based system provides access to home non-invasive ventilation (NIV) data, highlights therapy issues and facilitates prescription changes to optimise NIV and potentially rationalise patient follow up. Remote-adjustable volume-assured NIV modes with auto-EPAP and intelligent backup rates offer prospects for improved NIV titration. We have adopted these emerging technologies with aim of improving patient outcomes and service efficiency. Interrogation of remote monitoring NIV data will provide insights to the utility of new NIV modes.
Methods Between February and June 201767 patients (26 OHV, 21 COPD, 20 other cause hypoventilation) who had clinical indications for home NIV were commenced on iVAPS with auto-EPAP and intelligent backup rate mode NIV (Lumis, ResMed) with remote monitoring (Airview, ResMed) and their data was retrospectively reviewed.

Results 31 patients commenced NIV as a day-case rather than as inpatients (our previous service model), saving 93 occupied bed days. Patients required on average 3 data reviews and 1 telephone consultation. Remote prescription change - eg capping of pressures or adjustment of iVAPS targets to achieve symptomatic benefit or tolerance - was required in 38 patients, with 20 requiring more than 1 change. Adverse monitoring findings triggered beneficial early follow up day-case review in 12 patients. The majority of patients realised good NIV usage and benefit (based on standard monitoring parameters) after optimisation; 6 patients discontinued NIV use despite treatment adjustments. Disease-specific patterns of iVAPS pressure support provision with volume assured mode were noted. Auto-EPAP was poorly tolerated in COPD patients.

Conclusion 2-way remote monitoring highlights NIV therapy issues, allowing early remote or daycase troubleshooting and optimisation, which should translate to improved treatment outcomes. Remote monitoring facilitates day-case initiation, saving occupied bed days and outpatient visits vs our previous service model. 2-way monitoring identifies intractable noncompliant patients, expediting ventilator recovery. Disease-specific iVAPS provision patterns have been identified which will provide novel management and pathophysiological insights.

\section{P125 THE EFFECT OF PREVENTATIVE HYDROCOLLOID NASAL DRESSINGS IN ACUTE NON INVASIVE VENTILATION (NIV)-RELATED NASAL BRIDGE PRESSURE ULCERATION}

${ }^{1} \mathrm{~A}$ Bishopp, ${ }^{1} \mathrm{~A}$ Oakes, ${ }^{1} \mathrm{~A}$ Watson, ${ }^{2} \mathrm{~B}$ Chakraborty, ${ }^{1} \mathrm{G}$ Stygall, ${ }^{1} \mathrm{P}$ Antoine-Pitterson, ${ }^{1} \mathrm{E}$ Justice, ${ }^{1} \mathrm{~B}$ Rooke, ${ }^{1} \mathrm{~K}$ Stygall, ${ }^{1} \mathrm{R}$ Mukherjee. ${ }^{1}$ Birmingham Heartlands Hospital, Birmingham, UK; ${ }^{2}$ University of Birmingham, Birmingham, UK

\subsection{6/thoraxjnl-2017-210983.267}

Introduction There are over 4000 acute mask application episodes coded in the treatment of acute respiratory failure in the UK every month according to a 2017 survey (NCEPOD). Most guidelines on acute NIV use suggest good skin care strategies including regular mask pressure relief. However, data on the magnitude of the problem of nasal bridge pressure ulceration and the effect of proactive preventative steps (e.g., hydrocolloid dressings) remains scant. A previous smaller but similar survey in a district general hospital showed a trend in the reduction of Grade2 Pressure ulcer rates following change in practice but fell short of statistical significance (Stygall G, Morley K, Pickup L, et al. Thorax 2016. 71:3. A124-125.). We set out on a quality improvement project and systematically examined the effect of a proactive approach to prevent Grade2 Pressure ulcers in a dedicated ward-based Physiotherapy-led acute NIV service in a teaching hospital serving a population of about 400000 .

Methods In addition to the routine acute NIV data for the unit, additional data was collected from 30/10/14 to 31/08/ 2015 on: NIV mask used (model and size), total number of admissions with days of NIV (NIV bed-days) and nasal bridge tissue viability grading. This included a 12 month period before (period1) and a 12 month period after (period2) the 